\title{
Recent Progress on Catalysts towards Electrocatalytic Nitrogen Reduction Reaction
}

\author{
Xue YAO , Rui ZHAO , Zhengtong JI , Xingyou LANG, Yongfu ZHU*, Qing JIANG \\ Key Laboratory of Automobile Materials, Ministry of Education, School of Materials Science and Engineering, Jilin University, \\ Changchun, China
}

*Corresponding Author: Yongfu ZHU, Key Laboratory of Automobile Materials, Ministry of Education, School of Materials Science and Engineering, Jilin University, Changchun, 130022, China; yfzhu@jlu.edu.cn

\section{Abstract:}

The energy-intensive Haber-Bosch process currently dominants the production of ammonia $\left(\mathrm{NH}_{3}\right)$, an indispensable chemical for humans. For the sustainable development of society, highly efficient and green strategies to convert nitrogen $\left(\mathrm{N}_{2}\right)$ to $\mathrm{NH}_{3}$ are urgently required. Electrocatalytic $\mathrm{N}_{2}$ reduction reaction (eNRR) is universally regarded as a promising strategy owing to the mild operating conditions and renewable energy supply. The key for eNRR is the high-performance catalysts, which activate the inert N-N triple bond and thus decrease the energy barrier. Herein, the recent theoretical and experimental progress on eNRR catalysts at room temperature and ambient pressure is summarized, aiming to provide a reference for future design of high-performance eNRR catalysts.

Keywords: electrocatalysis; nitrogen reduction reaction; elemental catalysts; compound catalysts; single-atom catalysts

\section{Introduction}

Growing human population, expanding industrialization, and potential foreground as hydrogen energy carrier everlastingly increase the requirement of ammonia $\left(\mathrm{NH}_{3}\right) \cdot{ }^{[1-5]}$ In industry, currently, $\mathrm{NH}_{3}$ synthesis largely depends on the Haber-Bosch process, where atmospheric nitrogen $\left(\mathrm{N}_{2}\right)$ is reduced to $\mathrm{NH}_{3}$ using ironbased catalysts. ${ }^{[6-8]}$ However, such a reduction reaction is proceeded at high temperature and high pressure, and consequently it consumes tremendous amounts of fossil fuels and causes serious greenhouse gas emissions. ${ }^{[9-}$ ${ }^{12]}$ In this regard, it is pressing to replace the Haber-Bosch process with highly efficient and fossil-free pathways.

Inspired by the biological $\mathrm{N}_{2}$ fixation, which occurs in mild conditions on nitrogenase enzymes, where FeMo-cofactors are the catalytic active sites, ${ }^{[13,14]}$ electrocatalytic $\mathrm{N}_{2}$ reduction reaction (eNRR) is widely regarded as a promising pathway to synthesize $\mathrm{NH}_{3}$, where $\mathrm{N}_{2}$ and $\mathrm{H}_{2} \mathrm{O}$ are needed and the energy sources are renewable and clean. ${ }^{[15-22]}$ On the one hand, the N-N triple bond is strong with a bond energy of $941 \mathrm{~kJ} \mathrm{~mol}^{-}$ 1 , so the splitting of this bond is sluggish, resulting in the requirement of highly active catalysts. ${ }^{[1]}$ On the other hand, the active sites on catalyst surfaces towards
eNRR are usually also active for the reduction of $\mathrm{H}_{2} \mathrm{O}$ to hydrogen $\left(\mathrm{H}_{2}\right)$, leading to a low Faradaic efficiency, where proton-electron pairs $\left(\mathrm{H}^{+}+\mathrm{e}^{-}\right)$in the catalytic system are mainly consumed by the hydrogen evolution reaction (HER) rather than eNRR. ${ }^{[23-26]}$ Thus, sufficient eNRR catalysts should have high activity and excellent selectivity.

In the field of catalysts design, theoretical calculations provide the guidance while experimental explorations examine the guidance and give suggestions back. ${ }^{[20,27-31]}$ Hence, theoretical and experimental studies are both important for optimal catalysts. With this in mind, in this review, we summarize the recent theoretical and experimental progress on eNRR catalysts, mainly focus on the maximum energy barrier and the selectivity, where the former is determined by the change of free energy for the potential determining step (PDS) in theoretical calculations and the latter is reflected by the Faradaic efficiency in experimental tests.

\section{Reaction Mechanisms}

In general, electrocatalytic reduction of $\mathrm{N}_{2}$ to $\mathrm{NH}_{3}$ can be divided into the dissociative mechanism, the associative mechanism, and the Mars-van Krevelen mechanism, 
where the reduction is realized with hydrogenation induced by the proton-electron pairs $\left(\mathrm{H}^{+}+\mathrm{e}^{-}\right)$, as depicted in Figure 1. For the dissociative mechanism, the adsorbed $\mathrm{N}_{2}$ molecule is split into two $\mathrm{N}$ atoms, i.e. ${ }^{*} \mathrm{~N}$ and ${ }^{*} \mathrm{~N}$, where ${ }^{*}$ is an adsorption site of the catalyst. Large energy input is usually required to catalyze eNRR through this mechanism owing to the strong N-N triple bond. The associative mechanism can be further classified into three mechanisms, i.e. the distal mechanism, the alternative mechanism, and the enzymatic mechanism, where six hydrogenation steps are involved for every mechanism. In detail, standing-on adsorbed $\mathrm{N}_{2}$ molecule is reduced via the distal or alternative mechanism, while lying-on adsorbed one is reduced in the enzymatic mechanism. Moreover, for the distal mechanism, $\mathrm{a} \mathrm{NH}_{3}$ molecule is formed in the first three steps based on the distal $\mathrm{N}$ atom, and then the left $\mathrm{N}$ atom is further reduced into $\mathrm{NH}_{3}$ in the last three steps. Different to the case of the distal mechanism, two $\mathrm{N}$ atoms of an absorbed $\mathrm{N}_{2}$ molecule are alternately hydrogenated in the alternating and enzymatic mechanisms. As regards the Mars-van Krevelen mechanism, which usually occurs on the surfaces of nitrides, a surface $\mathrm{N}$ atom is first reduced to $\mathrm{NH}_{3}$, causing a $\mathrm{N}$-vacancy. $\mathrm{A} \mathrm{N}_{2}$ molecule will be adsorbed on such a vacancy, and the $\mathrm{N}$ atom out of the catalysts is hydrogenated to form the second $\mathrm{NH}_{3}$ molecule.

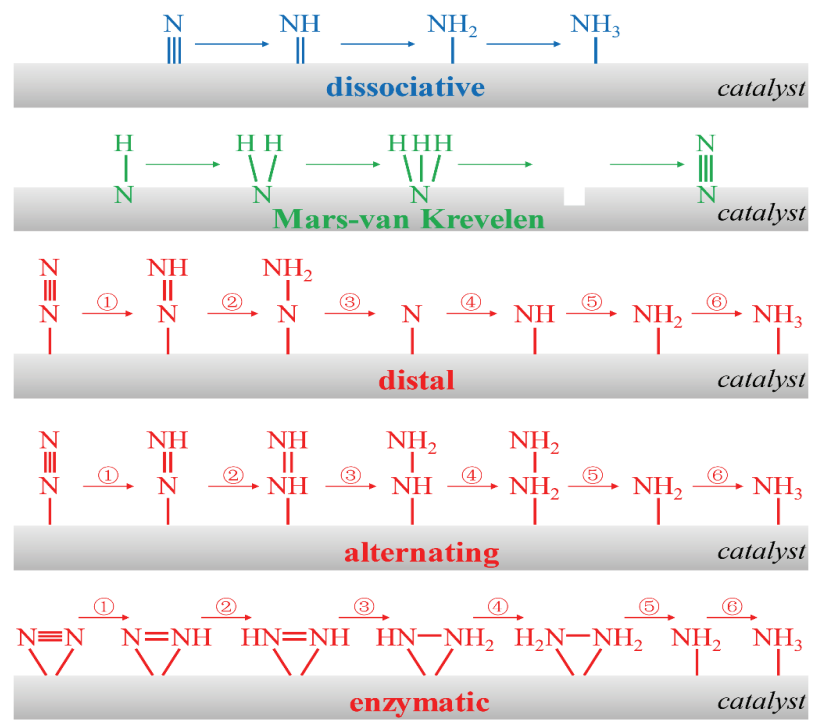

Figure 1. Scheme illustrations of possible eNRR mechanisms, including dissociative, Mars-van Krevelen, distal, alternating, and enzymatic mechanisms. For the Mars-van Krevelen mechanism, the rectangular blank denote a $\mathrm{N}$ vacancy. For distal, alternating, and enzymatic mechanisms, sixe elementary hydrogenation steps are labelled.

\section{Elemental Catalysts}

\subsection{Transition metal}

Due to the concept of "accept and backdonate", where the unoccupied d orbitals accept electrons from adsorbed $\mathrm{N}_{2}$ and the occupied d orbitals backdonate electrons to adsorbed $\mathrm{N}_{2}$ simultaneously, transition metal (TM) atoms usually have high eNRR activity. With the help of density functional theory (DFT) calculations, Skúlason et al. first explored the possibility of forming $\mathrm{NH}_{3}$ via eNRR on close-packed and stepped TM surfaces, ${ }^{[32]}$ using the computational hydrogen electrode (CHE) model developed by Nørskov and coworkers. ${ }^{[33]}$ According to the theoretical calculations, $\mathrm{Mo}, \mathrm{Fe}, \mathrm{Rh}$, and $\mathrm{Ru}$ are the most active TM surfaces (Figure 2). However, the major competing reaction, HER, will significantly decrease the Faradaic efficiency of eNRR on these TM surfaces. In contrast, the bonding of $\mathrm{N}_{2}$ is more stronger than that of $\mathrm{H}$ adatom on early TM surfaces, such as $\mathrm{Sc}, \mathrm{Y}, \mathrm{Ti}$, and $\mathrm{Zr}$, suggesting that $\mathrm{NH}_{3}$ should be the main product rather than $\mathrm{H}_{2}$ on these TM surfaces. Moreover, in Skúlason's work $^{[32]}$ the linear scaling relations were proposed, which shows that binding energy of all the $\mathrm{N}_{2} \mathrm{H}_{x}$ and $\mathrm{NH}_{x}$ species can be expressed on the basis of the binding energy of $\mathrm{N}$ adatom. After this pioneering theoretical work, Montoya et al. further highlighted that the linear scaling relations between ${ }^{*} \mathrm{~N}_{2} \mathrm{H}$ and ${ }^{*} \mathrm{NH}_{2}$ can be used to predict the overpotential of the eNRR process. ${ }^{[34]}$

According to above theoretical studies, ${ }^{[32,34]}$ especially that Mo is one of the TM atoms on the top of the volcano diagrams, Yang et al. synthesized (110)-oriented Mo nanofilm to catalyze eNRR, and achieved a Faradaic efficiency of $0.72 \%$ at an overpotential of $0.14 \mathrm{~V}$ and a rate of $\mathrm{NH}_{3}$ formation of $3.09 \times 10^{-11} \mathrm{~mol} \mathrm{~s}^{-1} \mathrm{~cm}^{-2}$ under an applied potential of $-0.49 \mathrm{~V}$ vs reversible hydrogen electrode (RHE). ${ }^{[35]}$ To reveal the origin of excellent performance of oriented Mo nanofilm, electrochemical tests were done in four Mo-based samples, including commercial Mo foil, Mo-A-R, Mo-D-R-1h, and Mo-D-R$5 \mathrm{~h}$, where $\mathrm{A}$ is the electrochemical anodization, $\mathrm{R}$ is the reduction process, $\mathrm{D}$ is the electro-deposition, and $1 \mathrm{~h}$ and $5 \mathrm{~h}$ are the time of electro-deposition. Among these four samples, Mo-D-R-5h shows the best catalytic performance, as shown in Figure 3. This is because Mo-D-R-5h possesses the highest (110) orientation and lowest (211) orientation, where $\mathrm{Mo}(110)$ plane can bind $\mathrm{N}$ adatom more strongly than $\mathrm{H}$ adatom while HER is the predominant reaction on Mo(211) plane.

In usual, noble metals have excellent activity to various reactions. Bao et al. synthesized tetrahexahedral gold nanorods (THH Au NRs), which are enclosed by stepped facet and composed of (210) and (310) subfacets, to endow the eNRR with a $\mathrm{NH}_{3}$ yield of 1.648 $\mu \mathrm{g} \mathrm{h}^{-1} \mathrm{~cm}^{-2}{ }^{[8]}$ According to DFT calculations, the PDS of $\mathrm{Au}(210)$ and $\mathrm{Au}(310)$ sub-facets are both the first hydrogenation of adsorbed $\mathrm{N}_{2}$. Similarly, taking $\mathrm{Au}$ as the raw materials, Nazemi et al. synthesized hollow gold nanocages (AuHNCs) to catalyze eNRR under ambient conditions, ${ }^{[36]}$ and it obtained a Faradaic efficiency of $30.2 \%$ at $-0.4 \mathrm{~V}$ vs. RHE and a $\mathrm{NH}_{3}$ yield of $3.9 \mu \mathrm{g} \mathrm{cm}^{-2} \mathrm{~h}^{-1}$ at -0.5 $\mathrm{V}$ vs. RHE in $0.5 \mathrm{M} \mathrm{LiClO}_{4}$ aqueous solution (Figure 4). Moreover, the eNRR rate was also evaluated using solid $\mathrm{Au}$ nanoparticles of various shape with similar nanoparticle concentrations, including rods (NRs), spheres (NSs), and 
cubes (NCs). ${ }^{[36]}$ The $\mathrm{NH}_{3}$ yield rate and Faradaic efficiency of solid $\mathrm{Au}$ nanoparticles were significantly lower than those of AuHNCs, where Au NRs are the worst among solid nanoparticles. This is because the number of coordination unsaturated surface atoms increases for nanoparticles with sharper edges, where coordination unsaturated surface atoms are active for adsorbing and reducing $\mathrm{N}_{2}$. The authors concluded that the cavity can entrap $\mathrm{N}_{2}$ molecules, resulting in the high frequency collisions with the hollow $\mathrm{Au}$ cages and increasing residence time of $\mathrm{N}_{2}$ molecules on the nanoparticle inner surface, and AuHNCs thus shows excellent eNRR performance. ${ }^{[36]}$ Besides $\mathrm{Au}, \mathrm{Ag}$ also has proved its worth in eNRR. Huang et al. synthesized Ag nanosheet to act as high-performance eNRR catalysts at ambient conditions. ${ }^{[37]}$ Electrochemical tests showed that a Faradaic efficiency of $4.8 \%$ and a NH3 yield rate of $4.62 \times 10^{-11} \mathrm{~mol} \mathrm{~s}^{-1} \mathrm{~cm}^{-2}$ at $0.60 \mathrm{~V}$ vs RHE were achieved on $\mathrm{Ag}$ nanosheet, and little changes in Faradaic efficiency and the $\mathrm{NH}_{3}$ yield rate can be seen after several times of recycling tests on this catalyst.

\subsection{Nonmetal}

Recently, Légaré et al. presented that $\mathrm{N}_{2}$ binding and reduction can be realized by a non-metal element, boron,

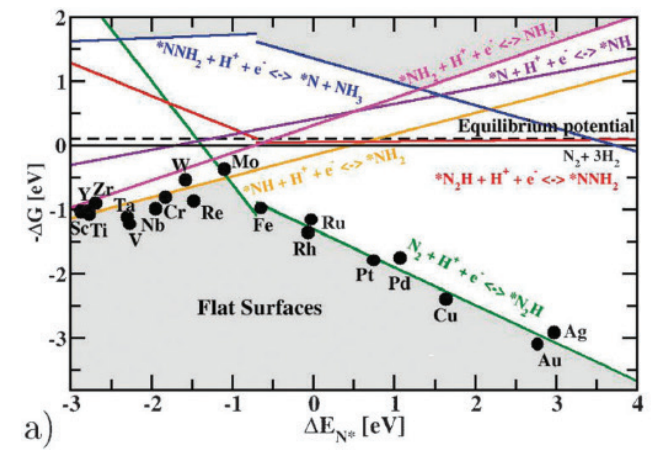

because the empty $\mathrm{sp}^{2}$ and occupied $\mathrm{p}$ orbitals of boron atom can accept electrons from and backdonate electrons to $\mathrm{N}_{2}{ }^{[38]}$ similar to the cases of TM atoms. Based on this observation, Liu et al. proposed that inorganic boron monolayer can catalyze eNRR with the help of DFT calculations. ${ }^{[39]}$ Two types of boron monolayer were considered, $\alpha$-sheet and $\beta_{12}$-sheet, and the maximum free energies of eNRR were $0.77 \mathrm{eV}$ and $1.22 \mathrm{eV}$ for them, respectively. Moreover, the authors found that the catalytic performance will be improved if two boron-sheets are deposited on $\mathrm{Ag}$ and $\mathrm{Cu}$ surfaces. In experiments, Zhang et al. synthesized boron nanosheet (BNS) to catalyze eNRR. The corresponding DFT calculations suggested that the boron atoms of both oxidized and $\mathrm{H}$-deactivated BNS can catalyze eNRR more effectively than the clean BNS. ${ }^{[40]}$

In addition, encouraged by the principle of "like dissolves like", Zhang et al. synthesized well-exfoliated fewlayer black phosphorous nanosheets as metal-free eNRR catalysts. Such catalysts were efficient for eNRR, and a high $\mathrm{NH}_{3}$ yield of $31.37 \mu \mathrm{g} \mathrm{h}^{-1} \mathrm{mg}_{\text {cat }}{ }^{-1}$ under ambient conditions can be attained. ${ }^{[41]}$ DFT calculations revealed that the selective reduction of $\mathrm{N}_{2}$ to $\mathrm{NH}_{3}$ occurs on the zigzag and diff-zigzag edges with the alternating mechanism due to the active orbitals and electrons.

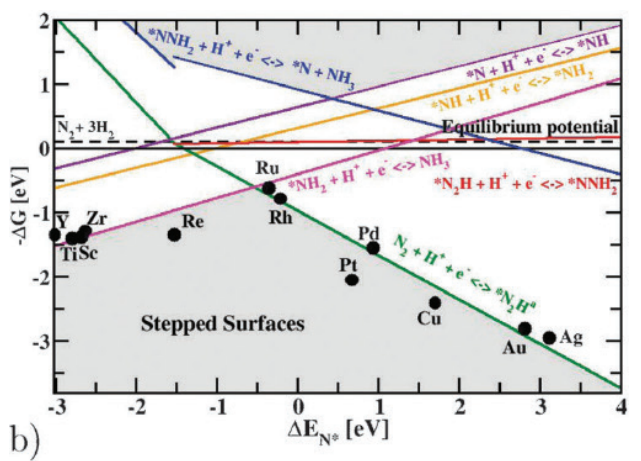

b)

Figure 2. Negative of the change of the free energy $(-\Delta G)$ is proportional to the onset potential, for all the charge transfer steps of ammonia synthesis as a function of the nitrogen binding energy at $\mathrm{U}=0 \mathrm{~V}$ for (a) flat surfaces and (b) stepped surfaces via the Heyrovsky-type associative mechanism. Reproduced from Ref.[32] with permission from the PCCP Owner Societies.

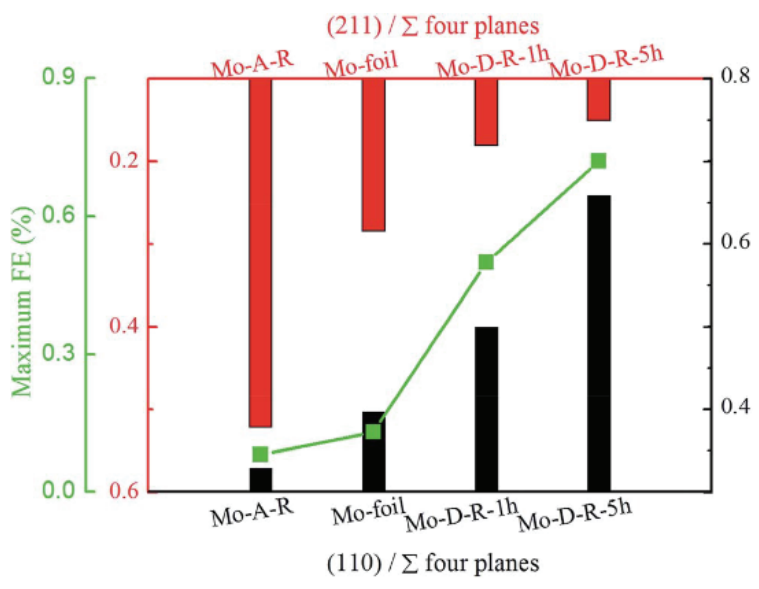

Figure 3. The relationship among the (110) orientation, (211) orientation and maximum Faradaic efficiency of four Mo-based electrochemical catalysts. Reproduced from Ref. [35] with permission from The Royal Society of Chemistry. 
(a)

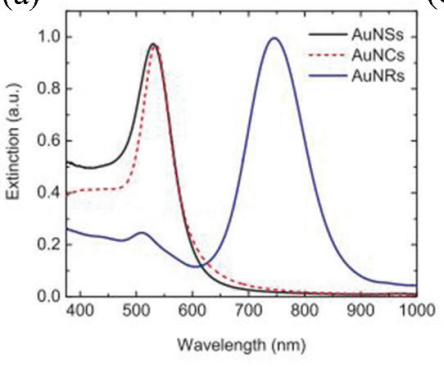

(c)

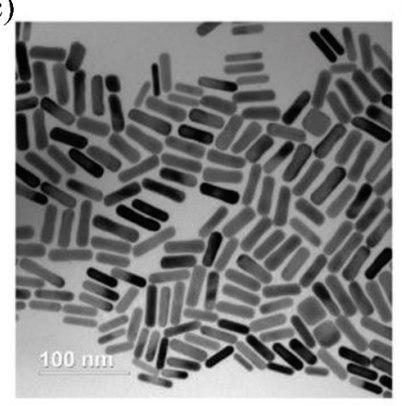

(b)

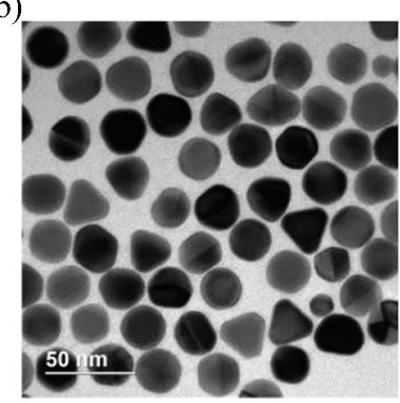

(d)

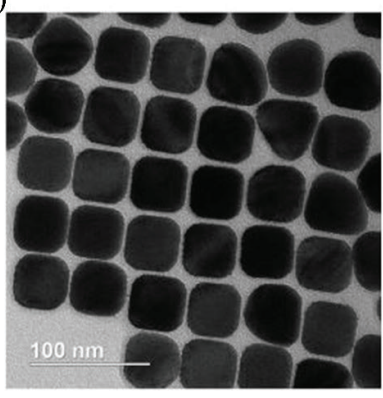

(e) $)_{30}$

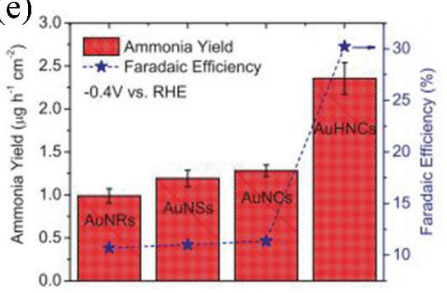

Figure 4. (a) UV-vis extinction spectra of AuNSs, AuNCs, and AuNRs. (b), (c), and (d) are the TEM images of AuNSs, AuNRs, and AuNCs, respectively. (e) Ammonia yield rate and Faradaic efficiency for nanoparticles of various types and shapes at the potential of - $0.4 \mathrm{~V}$ vs $\mathrm{RHE}$ in $0.5 \mathrm{M} \mathrm{LiClO}_{4}$ aqueous solution. Reproduced from Ref. [36] with permission from Elsevier B. V.

\section{Compound Catalysts}

\subsection{Single-atom catalysts}

Zhang et al. first proposed the single-atom catalyst in $2011,{ }^{[42]}$ where a single-atom catalyst with atomically dispersed Pt atoms anchored on the surface of iron oxide was prepared to catalyze the $\mathrm{CO}$ oxidation. After this, single-atom catalysts have been fascinating systems in the field of catalysis owing to $100 \%$ active atomic utilization efficiency and uniform active centers with low atomic coordination number. ${ }^{[43-46]}$ To expose the active centers as much as possible, $2 \mathrm{D}$ materials are the preferred supports. So, the following discussions are focused on single-atom catalysts towards eNRR with the supports of $2 \mathrm{D}$ materials. 4.1.1. Single-TM-atom catalysts

Owing to the concept of "accept and backdonate" as aforementioned, TM atoms are also welcomed active centers in single-atom catalysts. Since 2D materials are the popular supports, it is necessary to discuss the eNRR catalysts with graphene, the well-known 2D material, being the support. Inspired by the fact that Fe plays an important role in activating $\mathrm{N}_{2}$ in nitrogenases enzymes, ${ }^{[47]} \mathrm{Li}$ et al. proposed that the $\mathrm{FeN}_{3}$ active center supported on graphene was highly active for
$\mathrm{N}_{2}$ reduction. ${ }^{[48]}$ The $\mathrm{FeN}_{3}$ active center is highly spinpolarized, contributing to the adsorption and activation of $\mathrm{N}_{2}$ molecule. After evaluating the three possible associative mechanisms, PDS of the $\mathrm{FeN}_{3}$-embedded graphene is ${ }^{\star} \mathrm{N}_{2}+\mathrm{H}^{+}+\mathrm{e}^{-} \rightarrow{ }^{\star} \mathrm{N}_{2} \mathrm{H}$ or ${ }^{\star} \mathrm{NH}_{2}+\mathrm{H}^{+}+\mathrm{e}$ $\rightarrow{ }^{\star} \mathrm{NH}_{3}$. Moreover, according to the charge population analysis, the $\mathrm{FeN}_{3}$ active center acts as an electrons transmitter between gaphene and adsorbed species. ${ }^{[48]}$ Similarly, with Fe being the active center, Wei et al. proposed that $\mathrm{Fe}$-doped monolayer phosphorene as an eNRR catalyst using the spin-polarized DFT. ${ }^{[49]}$

As for the systematic study on the possibility of graphene as the support of eNRR catalysts, Choi et al. systematically studied the single-TM-atom catalysts with defective graphene being the support, where 30 $\mathrm{TM}$ atoms with La being the representative of La-Gd were embedded into four models, including $\mathrm{M} @ \mathrm{C}_{3}$, $\mathrm{M} @ \mathrm{C}_{4} \mathrm{M} @ \mathrm{~N}_{3}$, and $\mathrm{M} @ \mathrm{~N} \cdot{ }^{[50]}$ Among 120 catalysts, Ti@ $\mathrm{N}_{4}$ and $\mathrm{V} @ \mathrm{~N}_{4}$ have the best catalytic activity with the PDS of 0.69 and $0.87 \mathrm{eV}$ (Figure 5a, c), respectively, which are lower than that of the $\mathrm{Ru}(0001)$ stepped surface $(0.98 \mathrm{eV})$. Besides the high activity, significantly improved eNRR selectivity on these catalysts was also found, compared to the corresponding surface of bulk metal (Figure 5b). 
Such an excellent selectivity is the result of resemble effect, where ${ }^{*} \mathrm{H}$ on top site is the most stable for single-TM-atom catalysts while bridge or hollow site is preferred for pure metal. Moreover, due to the metal-support interaction, electronic structure of TM atoms are quite different from those of bulk TM. Charge transfer is universally present between metal and support, resulting in that the anchored TM atoms usually carry positive charge, hindering $\mathrm{H}^{+}$ approaching the metal. ${ }^{[50]}$

Similar to Fe, Mo plays a key role in FeMo-cofactor of nitrogenases enzymes as well, and Mo- $\mathrm{N}_{\mathrm{x}}$ complexes are promising eNRR molecular catalysts. ${ }^{[51,52]}$ So, incorporating Mo- $\mathrm{N}_{\mathrm{x}}$ moiety into $2 \mathrm{D}$ heterogeneous catalysts seems to be a highly efficient strategy for eNRR catalysts. In this regard, Zhao et al. proposed an advanced eNRR catalyst with Mo atoms anchored on the boron-vacancy of monolayer BN. ${ }^{[53]} \mathrm{Mo}$ is the optimal one between $\mathrm{Sc}$ to $\mathrm{Zn}, \mathrm{Mo}, \mathrm{Ru}, \mathrm{Rh}, \mathrm{Pd}$, and $\mathrm{Ag}$, because of its abilities to adsorb $\mathrm{N}_{2}$, selectively stabilize ${ }^{*} \mathrm{~N}_{2} \mathrm{H}$ and destabilize ${ }^{\star} \mathrm{NH}_{2}$. According to DFT calculation, lying-on and standing-on adsorbed $\mathrm{N}_{2}$ were both stable on Mo-embedded BN, and eNRR can be processed on Mo-embedded BN at a potential of $-0.35 \mathrm{~V}$ via the enzymatic mechanism. Similar to the $\mathrm{FeN}_{3}$-embedded graphene, central Mo atom in Mo-embedded $\mathrm{BN}$ is also spin-polarized, and $\mathrm{Mo}-\mathrm{N}_{3}$ acts as a electron transmitter in the whole reduction process. In addition, Ling et al. proposed that Mo supported on N-doped graphene can catalyze eNRR with a overpotential of $0.24 \mathrm{~V}$ via the enzymatic mechanism, ${ }^{[54]}$ and $\mathrm{Ou}$ et al. proposed that Mo supported on $\mathrm{N}$-doped black phosphorus can catalyze eNRR with a potential of $0.18 \mathrm{~V}$ via the distal mechanism. ${ }^{[55]}$

Besides $\mathrm{Fe}$ and Mo, which are important elements in cofactors of nitrogenases enzymes, other TM atoms also act well in boosting eNRR. Single Pt atom embedded in monolayer $\mathrm{g}-\mathrm{C}_{3} \mathrm{~N}_{4}$ as efficient single-atom catalysts for $\mathrm{NH}_{3}$ synthesis was explored by Yin et al. ${ }^{[56]}$ With DFT calculations, they found that $\mathrm{Pt} / \mathrm{g}-\mathrm{C}_{3} \mathrm{~N}_{4}$ has excellent activity to catalyze eNRR with a low potential of -0.24 $\mathrm{V}$ at ambient conditions. Moreover, $\mathrm{Pt} / \mathrm{g}-\mathrm{C}_{3} \mathrm{~N}_{4}$ is stable, and it has excellent conductivity. It is believed that the excellent activity of $\mathrm{Pt} / \mathrm{g}-\mathrm{C}_{3} \mathrm{~N}_{4}$ came from its significant deviation from the linear scaling. To further study the origin of this deviation, $\mathrm{N}_{2} \mathrm{H}$ and $\mathrm{NH}_{2}$ adsorptions on $\mathrm{Pt}(111)$, an isolated $\mathrm{Pt}$ atom, and $\mathrm{Pt} / \mathrm{g}-\mathrm{C}_{3} \mathrm{~N}_{4}$ were comparatively studied.[56] In comparison with $\mathrm{Pt}(111)$ and an isolated Pt atom, embedding the isolated Pt atom in g- $\mathrm{C}_{3} \mathrm{~N}_{4}$ completely cancels out the stability enhancement of ${ }^{\star} \mathrm{NH}_{2}$, while maintaining the stability of ${ }^{\star} \mathrm{N}_{2} \mathrm{H}$. The single Pt atom and g- $\mathrm{C}_{3} \mathrm{~N}_{4}$ work in concert to stabilize ${ }^{\star} \mathrm{N}_{2} \mathrm{H}$ and destabilize ${ }^{\star} \mathrm{NH}_{2}$, providing highly active sites for eNRR.

Embedding TM active centers into 2D materials has been extensive studied, and great progress has been made. Meanwhile, it is notable that discovering new materials is always attractive for new advances. In eNRR, by means of DFT calculations, Chen et al. designed a new cobweb-like 2D $\mathrm{MoC}_{6}$ structure (Figure 6a), and they found that $\mathrm{MoC}_{6}$ can efficiently realize the $\mathrm{N}_{2}$ to $\mathrm{NH}_{3}$ process under ambient conditions. ${ }^{[57]}$ They suggested a feasible pathway to synthesis the $\mathrm{MoC}_{6}$ structure, where two process are involved: the synthesis of graphyne, and the deposition of Mo atoms. For the catalytic process, $\mathrm{N}_{2}$ is adsorbed on the bridge site from the orientation relationship of the frontier molecular orbitals (Figure $6 \mathrm{~b}$ ), and the following reduction of $\mathrm{N}_{2}$ to $\mathrm{NH}_{3}$ can be realized at a potential of $-0.54 \mathrm{~V}$ via the enzymatic pathway (Figure 6c). Moreover, the adsorption energy of $\mathrm{N}_{2}$ is $-0.36 \mathrm{eV}$, stronger than that of $\mathrm{H}$ atom $(-0.15$ $\mathrm{eV}$ ), showing that competing HER is inhibited.

\subsubsection{Single-nonmetal-atom catalysts}

The unique electronic structure of boron atom enables it to be alternative element for TM atoms as aforesaid, which means that single-nonmetal-atom catalysts and metal-free catalysts are possible for boosting eNRR. $\mathrm{Yu}$ et al. synthesized a boron-doped graphene as an efficient metal-free eNRR catalyst. ${ }^{[58]}$ Electron density redistribution in the graphene support is realized by doping boron, and the electron-deficient doping boron increases the adsorption energy of $\mathrm{N}_{2}$ molecules. Among three boron-doped graphene structures, including $\mathrm{BC}_{3}, \mathrm{BC}_{2} \mathrm{O}$, and $\mathrm{BCO}_{2}, \mathrm{BC}_{3}$ presents the lowest energy barrier of $0.43 \mathrm{eV}$ for eNRR. After electrochemical tests, an excellent performance with a $\mathrm{NH}_{3}$ production rate of $9.8 \mu \mathrm{g} \cdot \mathrm{hr}^{-1} \cdot \mathrm{cm}^{-2}$ and a Faradic efficiency of $10.8 \%$ at $0.5 \mathrm{~V}$ vs RHE was presented, while the performance of undoped graphene is poor. ${ }^{[58]}$ As for theoretical explorations, Ling et al. proposed that $\mathrm{N}_{2}$ molecule can be efficiently adsorbed and reduced to $\mathrm{NH}_{3}$ on $\mathrm{B} / \mathrm{g}-\mathrm{C}_{3} \mathrm{~N}_{4}$, and the whole reduction process can be proceeded at a low potential of $0.20 \mathrm{~V}$ via the enzymatic mechanism. Meanwhile, B/g$\mathrm{C}_{3} \mathrm{~N}_{4}$ can absorb visible light well, which renders it ideal for solar-driven reduction of $\mathrm{N}_{2}{ }^{\left[{ }^{[59]} \mathrm{Ji}\right.}$ et al. proposed that a boron-interstitial-doped $\mathrm{C}_{2} \mathrm{~N}$ layer can be an excellent metal-free eNRR catalyst. The doping boron is positive and magnetic, contributing to tis high activity and high selectivity. The eNRR process prefers to proceed via the enzymatic mechanism with a potential of $0.15 \mathrm{~V} \cdot{ }^{[60]} \mathrm{Lv}$ et al. proposed that $\mathrm{B} / \mathrm{g}-\mathrm{CN}$ can activate the adsorbed $\mathrm{N}_{2}$ and further convert it to $\mathrm{NH}_{3}$ with a overpotential of $0.15 \mathrm{~V}$, and the activation barrier of PDS is $0.61 \mathrm{eV}^{[61]}$ Furthermore, Liu et al. modeled 21 catalysts with boron atoms anchored on eight 2D materials, including graphene, boron nitride, boron sulfide, black phosphrous, S-triazine-based g- $\mathrm{C}_{3} \mathrm{~N}_{4}$, tri-s-triazine-based g- $\mathrm{C}_{3} \mathrm{~N}_{4}, \mathrm{~h}-\mathrm{MoS}_{2}$, and T-MoS , as shown in Figure $7 \mathrm{a}^{\left[{ }^{[2]}\right]}$ Among these eNRR catalysts, single boron atoms supported on graphene or substituted into h-MoS shows best catalytic activity towards eNRR. According to the charge analysis, the authors found that the catalytic activity is highly related to the charge transfer between the boron atom and the substrate. Boron site with more electrons has higher possibility to inject electron and activate $\mathrm{N}_{2}$, and boron site with positive charge is obviously beneficial to inhibit HER, as indicated in Figure $7 b^{[62]}$ 
(a)

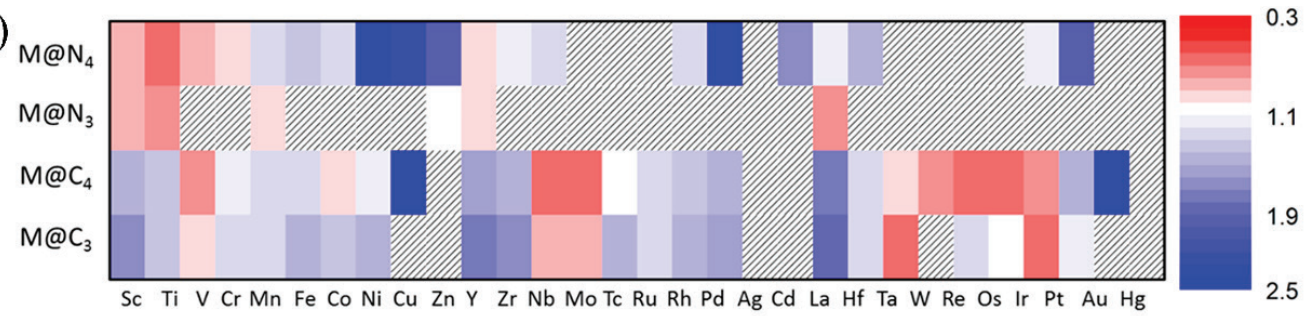

(b)

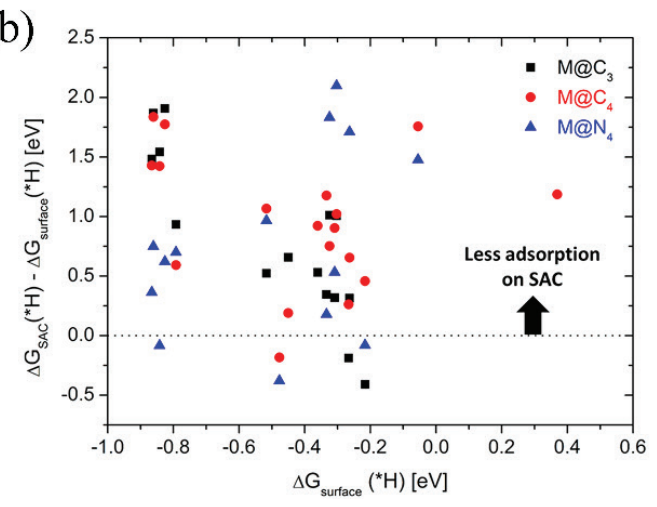

(c)

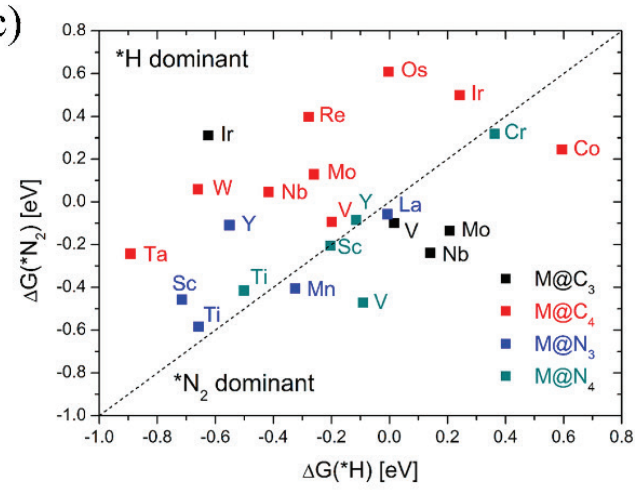

Figure 5. (a) Free energy $(\Delta \mathrm{G})$ of PDS on 120 single-atom catalysts, where single-atom catalysts filled with patterns represent thermodynamically unstable single-atom catalysts. (b) Difference between $\mathrm{H}$ adsorption free energy on the single-atom catalysts $\left.\left(\Delta \mathrm{G}_{\mathrm{SAC}}{ }^{*} \mathrm{H}\right)\right)$ and adsorption free energy on the surface $\left.\left(\Delta \mathrm{G}_{\text {surface }}{ }^{*} \mathrm{H}\right)\right)$ of the same metal atoms. (c) Calculated $\Delta \mathrm{G}\left({ }^{*} \mathrm{H}\right)$ and $\Delta \mathrm{G}\left({ }^{*} \mathrm{~N}_{2}\right)$ on single-atom catalysts that satisfy $\Delta \mathrm{G}_{\mathrm{PDS}} \leq 1.0 \mathrm{eV}$. Dashed line indicates $\Delta \mathrm{G}\left({ }^{*} \mathrm{H}\right)=$ $\Delta \mathrm{G}\left({ }^{\star} \mathrm{N}_{2}\right)$. Reproduced from Ref. [50] with permission from American Chemical Society.

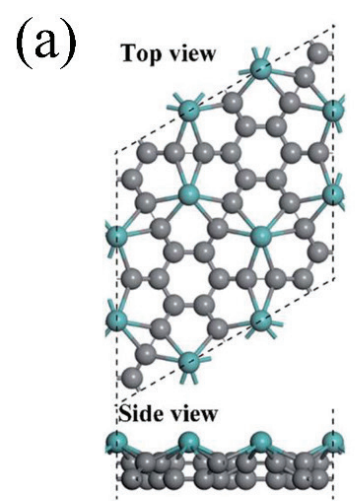

(b)

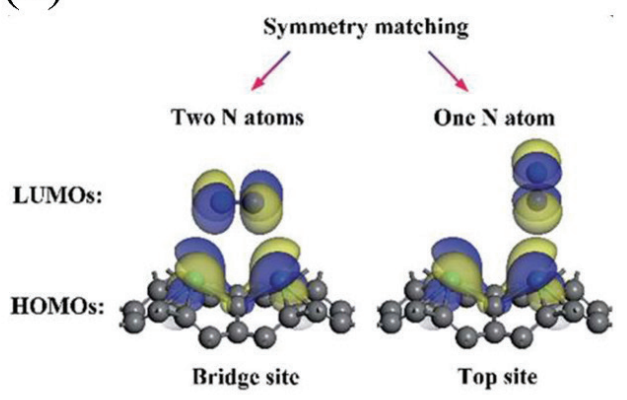

(c)

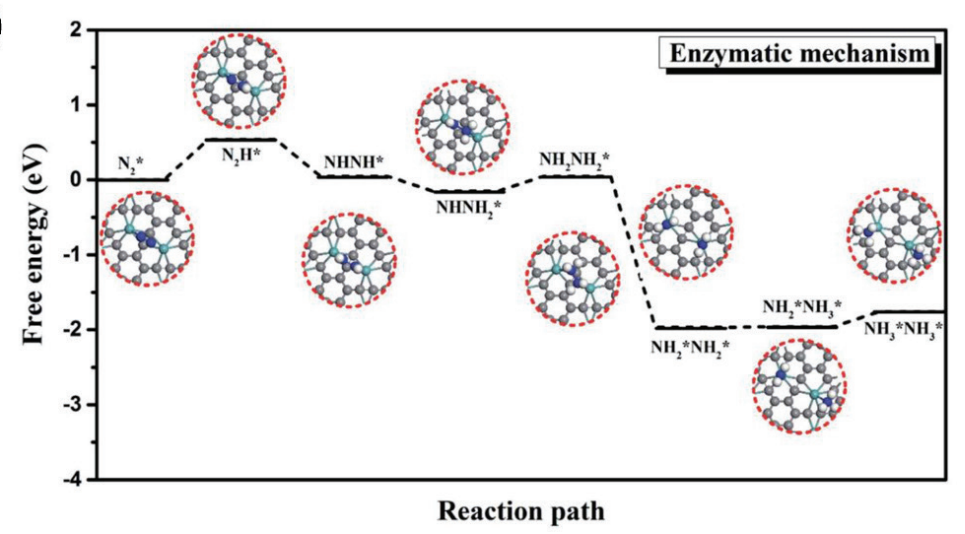

Figure 6. (a) Top and side views of the $2 \mathrm{D} \mathrm{MoC}_{6}$, where black balls denote $\mathrm{C}$ atoms and the other balls denotes Mo atoms.(b) Symmetry matching between the lowest unoccupied molecular orbitals (LUMOs) of $\mathrm{N}_{2}$ and the highest occupied molecular orbitals (HOMOs) of $\mathrm{MoC}_{6}$, including bridge site and top site. The yellow and blue shadows represent frontier molecular orbitals. (c) The enzymatic mechanism for eNRR on $\mathrm{MoC}_{6}$. The free energy profiles and the structures of intermediates are shown in the reaction path. Reproduced from Ref. [57] with permission from The Royal Society of Chemistry. 
(a)

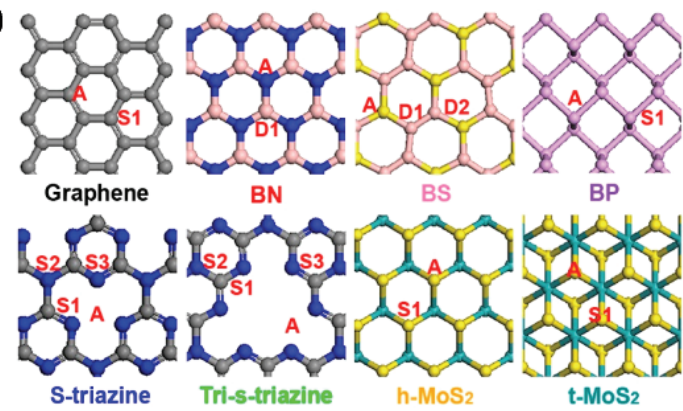

(b)

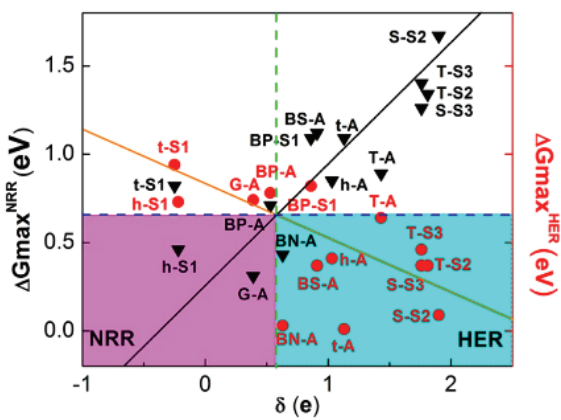

Figure 7. Proposed 2D materials and potential B-sites. The numbers indicate different bonding environments described in the text. Black, blue, rose, yellow, purple, and cyan spheres represent C, N. B, S, P, and Mo, respectively. (b) Computational screening of 14 catalyst combinations in terms of $\Delta \mathrm{G}_{\max }{ }_{\text {HER }}$ and $\Delta \mathrm{G}_{\max }{ }_{\text {NRR }}$ vs Bader charge ( $\delta$, in units of e) of single boron in or on a 2D substrate. Reproduced from Ref. [62] with permission from American Chemical Society.

(a)

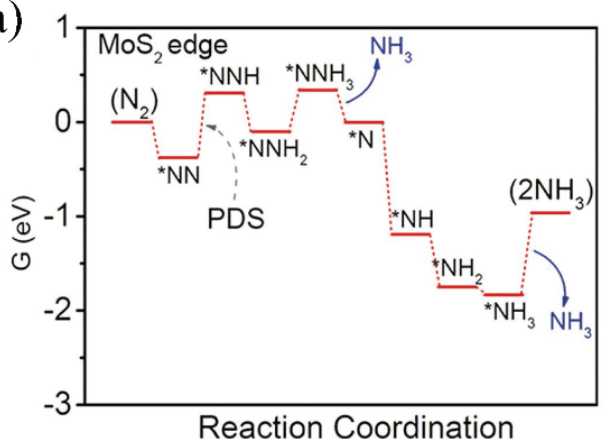

(b)

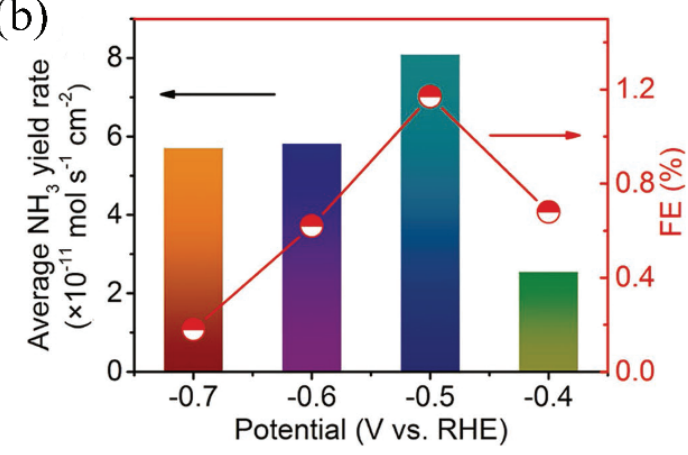

Figure 8. Free-energy profile for eNRR at $\mathrm{MoS}_{2}$ edge site. (b) Average $\mathrm{NH}_{3}$ yields and Faradaic efficiencies (FEs) of $\mathrm{MoS}_{2} / \mathrm{CC}$ at different potentials in $0.1 \mathrm{M} \mathrm{Na}_{2} \mathrm{SO}_{4}$ at room temperature and ambient pressure. Reproduced from Ref. [66] with permission from Wiley- $\mathrm{VCH}$.

\subsection{Transition metal nitrides}

Abghoui et al. proposed that the transition metal mononitrides can act as cost-efficient catalysts to convert $\mathrm{N}_{2}$ molecule to $\mathrm{NH}_{3}$ under ambient conditions, where a low applied bias is only required. ${ }^{[63]}$ By means of DFT calculations, the most promising catalysts are $\mathrm{VN}, \mathrm{ZrN}$, $\mathrm{NbN}$ and $\mathrm{CrN}$ among 25 considered TM mononitrides. Moreover, the competing HER is inhibited for above four mononitrides, which differs to the cases of pure metals. Since the structural particularity of TM mononitrides, the authors explored the poisoning and possible decomposition, and they pointed that, under operating conditions, $\mathrm{ZrN}$, $\mathrm{NbN}$ and $\mathrm{CrN}$ should be single-crystal surfaces because polycrystalline surfaces may be decomposed, while polycrystalline surfaces of $\mathrm{VN}$ may be used. ${ }^{[63]} \mathrm{Li}$ et al. proposed that transition metal binitride nanosheet, $\mathrm{MoN}_{2}$, as an eNRR catalyst at ambient conditions with the scheme of DFT. ${ }^{[64]}$ Different to transition metal mononitrides, $\mathrm{MoN}_{2}$ is a 2D layered material. According to calculations, $\mathrm{MoN}_{2}$ acts well in adsorbing and activating $\mathrm{N}_{2}$ molecule, but large energy is required to refresh the $\mathrm{MoN}_{2}$ surface. To improve the performance, Fe-doping was used, which can significantly improve it to proceed the whole reduction reaction with an overpotential of $0.47 \mathrm{~V}$.

In experiments, Zhang et al. synthesized MoN nanosheets array grown on carbon cloth (MoN NA/CC) to catalyze eNRR. ${ }^{[65]}$ This catalyst achieved a NH3 yield of $3.01 \times 10^{-10} \mathrm{~mol} \mathrm{~s}^{-1} \mathrm{~cm}^{-2}$ and a Faradaic efficiency of $1.15 \%$ at $-0.3 \mathrm{~V}$ vs RHE in $0.1 \mathrm{M} \mathrm{HCl}$ under ambient conditions. After theoretical calculations of free energy profile, the PDS of MoN NA/CC to catalyze eNRR is the second protonation of the surface $\mathrm{N}$.

\subsection{Transition metal dichalcogenides}

As emerging 2D materials, transition metal dichalcogenides have attracted worldwide interests because of the unique physical, chemical, and mechanical properties. Zhang et al. first explored the possibility of $\mathrm{MoS}_{2}$ as an eNRR catalyst. [66] To evaluate the possibility of MoS to catalyze eNRR, the electronic structures of $\mathrm{MoS}_{2}$ and the energy profile of eNRR were explored using DFT calculations. The results showed that the basal plane is inert to absorb $\mathrm{N}_{2}$ molecule while the edge appeared to be active, and the energy profile indicted that the PDS is the first hydrogenation of ${ }^{\star} \mathrm{N}_{2}$ with a barrier of $0.68 \mathrm{eV}$ (Figure 8a). After this, the authors synthesized $\mathrm{MoS}_{2}$ nanosheet array grown on carbon cloth $\left(\mathrm{MoS}_{2} / \mathrm{CC}\right)$ to catalyze eNRR, and the $\mathrm{NH}_{3}$ yield rate and Faradaic efficiency can reach $8.08 \times 10^{-11} \mathrm{~mol} \mathrm{~s}^{-1} \mathrm{~cm}^{-2}$ and $1.17 \%$, respectively. Moreover, Li et al. further improved the performance of $\mathrm{MoS}_{2}$ on eNRR by synthesizing defect-rich $\mathrm{MoS}_{2}$ nanoflowers, where the active centers are on the basal 
plane. ${ }^{[67]}$ In $0.1 \mathrm{M} \mathrm{Na}_{2} \mathrm{SO}_{4}$, this catalyst attained a Faradic effciency of $8.34 \%$ and a $\mathrm{NH}_{3}$ yield of $29.28 \mu \mathrm{g} \mathrm{h}^{-1} \mathrm{mg}^{-1}$ cat. at $-0.40 \mathrm{~V}$ versus RHE, significantly higher than those of defect-free $\mathrm{MoS}_{2}$ nanosheet $\left(2.18 \%\right.$ and $\left.13.41 \mu \mathrm{g} \mathrm{h}^{-1} \mathrm{mg}^{-1}{ }_{\text {cat }}\right)$. The vacancy with one missing Mo atom and two missing $\mathrm{S}$ atoms was regarded as the active sites, and the PDS of the eNRR process was calculated to be ${ }^{\star} \mathrm{NH}_{2} \rightarrow{ }^{\star} \mathrm{NH}_{3}$ with the PDS of $0.60 \mathrm{eV}$, which is less than the edge Mo atoms $(0.68 \mathrm{eV}) .^{[66]}$

The edge Mo atoms and the defect in basal plane of $\mathrm{MoS}_{2}$ can be active centers for eNRR, suggesting the potential of transition metal dichalcogenides as efficient eNRR catalysts. In addition, as a $2 \mathrm{D}$ material, $\mathrm{MoS}_{2}$ absolutely can act as support to anchor the active centers. Suryanto et al. synthesized $\mathrm{Ru} / \mathrm{MoS}_{2}$ to catalyze eNRR, and a Faradaic efficiency of $17.6 \%$ and a $\mathrm{NH}_{3}$ yield rate of $1.14 \times 10^{-10} \mathrm{~mol}$ $\mathrm{cm}^{-2} \mathrm{~s}^{-1}$ were obtained at $50{ }^{\circ} \mathrm{C}$.[68] The corresponding DFT calculations carried out with a hcp $\mathrm{Ru}_{117}$ nanocluster on $\mathrm{MoS}_{2}$ suggested that PDS is ${ }^{\star} \mathrm{NH}_{2} \rightarrow{ }^{*} \mathrm{NH}_{3}$ with a barrier of $0.35 \mathrm{eV}$ through the dissociative mechanism. In this model, the S-vacancies on $\mathrm{MoS}_{2}$ provides a fundamental role in eNRR process to provide $\mathrm{H}$ adatom, where the already formed ${ }^{\star} \mathrm{H}$ can be transferred to nearby bound ${ }^{\star} \mathrm{N}_{2}$ or ${ }^{*} \mathrm{NH}_{\mathrm{x}} \cdot{ }^{[68]}$

Besides conventional $\mathrm{MoS}_{2}$, a new class of $2 \mathrm{D}$ materials called "Janus" MoSSe has been recently synthesized with Mo atomic layer being sandwiched between S and Se ones. [69, 70] Similar to $\mathrm{MoS}_{2}$, MoSSe has shown good catalytic performances. ${ }^{[11,72]}$ As for its possible application in eNRR, Li et al. performed a theoretical screening of different TM atoms anchored on the S- or Se-vacancy of monolayer MoSSe as efficient eNRR catalysts. ${ }^{[73]}$ According to the screening, Mo atom anchored on the S-vacancy presents the highest activity with a potential of $-0.49 \mathrm{~V}$, while HER is significantly inhibited due to larger free energy of ${ }^{\star} \mathrm{H}$ adsorption.

\subsection{Transition metal carbides}

From the $\mathrm{d}$ orbital theory, transition metal carbides should have good adsorption ability for electron-enriched adsorbates because of the unoccupied d orbitals. ${ }^{[74]}$ Among various transition metal carbides, $\mathrm{Mo}_{2} \mathrm{C}$ has exhibited a potential application in catalytic hydrogenation. ${ }^{[75,76]}$ Moreover, the Mo-based materials have shown excellent performance in eNRR as stated above. According to this, Cheng et al. synthesized $\mathrm{Mo}_{2} \mathrm{C}$ nanodots supported on ultrathin carbon nanosheets $\left(\mathrm{Mo}_{2} \mathrm{C} / \mathrm{C}\right)$ to fix $\mathrm{N}_{2}$ molecule and catalyze the eNRR. The as-synthesized $\mathrm{Mo}_{2} \mathrm{C} / \mathrm{C}$ nanosheets presented promising catalytic performance with a $\mathrm{NH}_{3}$ yield rate of $11.3 \mu \mathrm{g} \mathrm{h}^{-1} \mathrm{mg}^{-1}$ cat. and a Faradic effciency of $7.8 \%$ under ambient conditions. ${ }^{[77]}$

Outlook: Exploring highly-performance eNRR catalysts has emerged as a new research hotspot. In theoretical calculations, various catalysts show excellent catalytic activity, especially the single-atom catalysts. However, most practically synthesized catalysts towards eNRR are based on the active centers from the defects. Though several single-atom eNRR catalysts have been fabricated, the corresponding loading of active site is usually kept at a low level or the heteroatoms are usually aggregated to nanoclusters. On the other hand, theoretical calculations neglect some important respects, such as the electrodecatalyst interface, the catalyst-electrolyte interface, and the mass and electron transportation. More instructive theoretical calculation should be developed, and consequently bridge the gap between theoretical calculations and experiments.

Acknowledgement:This project is financially supported by the National Natural Science Foundation of China (Nos. 61674069 and 51631004), the Key Scientific and Technological Research and Development Project of Jilin Province (20180201080GX), the Fundamental Research Funds for the Central Universities, and the Program for JLU Science and Technology Innovative Research Team (No. 2017TD-09).

\section{References}

[1] S.L. Foster, S.I.P. Bakovic, R.D. Duda, S. Maheshwari, R.D. Milton, S.D. Minteer, M.J. Janik, J.N. Renner, L.F. Greenlee, Catalysts for nitrogen reduction to ammonia, Nature Catalysis 1(7) (2018) 490.

[2] J. Guo, P. Chen, Catalyst: NH3 as an energy carrier, Chem 3(5) (2017) 709-712.

[3] C.H. Christensen, T. Johannessen, R.Z. Sørensen, J.K. Nørskov, Towards an ammonia-mediated hydrogen economy?, Catal. Today 111(1-2) (2006) 140-144.

[4] S.J. Li, D. Bao, M.M. Shi, B.R. Wulan, J.M. Yan, Q. Jiang, Amorphizing of Au nanoparticles by CeOx-RGO hybrid support towards highly efficient electrocatalyst for $\mathrm{N}_{2}$ reduction under ambient conditions, Adv. Mater. 29(33) (2017) 1700001.

[5] M.M. Shi, D. Bao, S.J. Li, B.R. Wulan, J.M. Yan, Q. Jiang, Anchoring $\mathrm{PdCu}$ amorphous nanocluster on graphene for electrochemical reduction of $\mathrm{N}_{2}$ to $\mathrm{NH}_{3}$ under ambient conditions in aqueous solution, Advanced Energy Materials 8(21) (2018) 1800124.

[6] Y. Ashida, K. Arashiba, K. Nakajima, Y. Nishibayashi, Molybdenum-catalysed ammonia production with samarium diiodide and alcohols or water, Nature 568(7753) (2019) 536.

[7] R.D. Milton, R. Cai, S. Abdellaoui, D. Leech, A.L. De Lacey, M. Pita, S.D. Minteer, Bioelectrochemical Haber-Bosch Process: An Ammonia-Producing $\mathrm{H}_{2} / \mathrm{N}_{2}$ Fuel Cell, Angew. Chem. Int. Ed. 56(10) (2017) 2680-2683.

[8] D. Bao, Q. Zhang, F.L. Meng, H.X. Zhong, M.M. Shi, Y. Zhang, J.M. Yan, Q. Jiang, X.B. Zhang, Electrochemical reduction of $\mathrm{N}_{2}$ under ambient conditions for artificial $\mathrm{N}_{2}$ fixation and renewable energy storage using $\mathrm{N}_{2} / \mathrm{NH}_{3}$ cycle, Adv. Mater. 29(3) (2017) 1604799.

[9] P.J. Chirik, Nitrogen fixation: one electron at a time, Nature chemistry 1(7) (2009) 520. 
[10] Z.W. Chen, J.M. Yan, Q. Jiang, Single or Double: Which Is the Altar of Atomic Catalysts for Nitrogen Reduction Reaction?, Small Methods (2018) 1800291.

[11] X. Cui, C. Tang, Q. Zhang, A review of electrocatalytic reduction of dinitrogen to ammonia under ambient conditions, Advanced Energy Materials 8(22) (2018) 1800369.

[12] B.H. Suryanto, H.-L. Du, D. Wang, J. Chen, A.N. Simonov, D.R. MacFarlane, Challenges and prospects in the catalysis of electroreduction of nitrogen to ammonia, Nature Catalysis (2019) 1.

[13] B.K. Burgess, D.J. Lowe, Mechanism of molybdenum nitrogenase, Chem. Rev. 96(7) (1996) 2983-3012.

[14] R.R. Eady, Structure- function relationships of alternative nitrogenases, Chem. Rev. 96(7) (1996) 3013-3030.

[15] Y. Wan, J. Xu, R. Lv, Heterogeneous electrocatalysts design for nitrogen reduction reaction under ambient conditions, Mater. Today (2019).

[16] X. Liu, Y. Jiao, Y. Zheng, M. Jaroniec, S.-Z. Qiao, Building Up a Picture of the Electrocatalytic Nitrogen Reduction Activity of Transition Metal Single-Atom Catalysts, J. Am. Chem. Soc. 141(24) (2019) 9664-9672.

[17] X. Guo, H. Du, F. Qu, J. Li, Recent progress in electrocatalytic nitrogen reduction, Journal of Materials Chemistry A 7(8) (2019) 3531-3543.

[18] H. Zhou, J. Li, Z. Wen, Q. Jiang, Tuning catalytic activity of single Mo atom supported on graphene for nitrogen reduction via Se atom doping, PCCP (2019).

[19] Y. Zhang, H. Du, Y. Ma, L. Ji, H. Guo, Z. Tian, H. Chen, H. Huang, G. Cui, A.M. Asiri, Hexagonal boron nitride nanosheet for effective ambient $\mathrm{N} 2$ fixation to $\mathrm{NH} 3$, Nano Research 12(4) (2019) 919-924.

[20] J. Zhao, X. Ren, X. Li, D. Fan, X. Sun, H. Ma, Q. Wei, D. Wu, High-performance N 2-to-NH 3 fixation by a metal-free electrocatalyst, Nanoscale 11(10) (2019) 4231-4235.

[21] X. Li, X. Ren, X. Liu, J. Zhao, X. Sun, Y. Zhang, X. Kuang, T. Yan, Q. Wei, D. Wu, A MoS 2 nanosheet-reduced graphene oxide hybrid: an efficient electrocatalyst for electrocatalytic $\mathrm{N} 2$ reduction to $\mathrm{NH} 3$ under ambient conditions, Journal of Materials Chemistry A 7(6) (2019) 2524-2528.

[22] Y. Liu, M. Han, Q. Xiong, S. Zhang, C. Zhao, W. Gong, G. Wang, H. Zhang, H. Zhao, Dramatically Enhanced Ambient Ammonia Electrosynthesis Performance by In-Operando Created Li-S Interactions on MoS2 Electrocatalyst, Advanced Energy Materials (2019) 1803935.

[23] A.R. Singh, B.A. Rohr, J.A. Schwalbe, M. Cargnello, K. Chan, T.F. Jaramillo, I. Chorkendorff, J.K. Nørskov, Electrochemical Ammonia Synthesis The Selectivity Challenge, ACS Publications, 2016.

[24] Y. Huang, T. Yang, L. Yang, R. Liu, G. Zhang, J. Jiang, Y. Luo, P. Lian, S. Tang, Graphene-Boron Nitride Hybrid
Supported Single Mo Atom Electrocatalysts for Efficient Nitrogen Reduction Reaction, Journal of Materials Chemistry A (2019).

[25] L. Xia, J. Yang, H. Wang, R. Zhao, H. Chen, W. Fang, A.M. Asiri, F. Xie, G. Cui, X. Sun, Sulfur-doped graphene for efficient electrocatalytic N 2-to-NH 3 fixation, Chem. Commun. 55(23) (2019) 3371-3374.

[26] Y. Ying, K. Fan, X. Luo, H. Huang, Predicting two-dimensional pentagonal transition metal monophosphides for efficient electrocatalytic nitrogen reduction, Journal of Materials Chemistry A 7(18) (2019) 11444-11451.

[27] Z.W. Seh, J. Kibsgaard, C.F. Dickens, I. Chorkendorff, J.K. Nørskov, T.F. Jaramillo, Combining theory and experiment in electrocatalysis: Insights into materials design, Science 355(6321) (2017) eaad4998.

[28] Z.W. Chen, W. Gao, W.T. Zheng, Q. Jiang, Steric Hindrance in Sulfur Vacancy of Monolayer MoS2 Boosts Electrochemical Reduction of Carbon Monoxide to Methane, ChemSusChem 11(9) (2018) 1455-1459.

[29] C.-X. Zhao, G.-X. Zhang, W. Gao, Q. Jiang, Single metal atoms regulated flexibly by a $2 \mathrm{D}$ InSe substrate for CO 2 reduction electrocatalysts, Journal of Materials Chemistry A 7(14) (2019) 8210-8217.

[30] F. Gao, X. Tang, H. Yi, S. Zhao, C. Li, J. Li, Y. Shi, X. Meng, A review on selective catalytic reduction of NOx by $\mathrm{NH} 3$ over $\mathrm{Mn}$-based catalysts at low temperatures: catalysts, mechanisms, kinetics and DFT calculations, Catalysts 7(7) (2017) 199.

[31] M. Krajčí, J. Hafner, Intermetallic compounds as selective heterogeneous catalysts: insights from DFT, ChemCatChem 8(1) (2016) 34-48.

[32] E. Skulason, T. Bligaard, S. Gudmundsdóttir, F. Studt, J. Rossmeisl, F. Abild-Pedersen, T. Vegge, H. Jonsson, J.K. Nørskov, A theoretical evaluation of possible transition metal electro-catalysts for N 2 reduction, PCCP 14(3) (2012) 1235-1245.

[33] E. Skúlason, V. Tripkovic, M.E. Björketun, S. Gudmundsdottir, G. Karlberg, J. Rossmeisl, T. Bligaard, H. Jónsson, J.K. Nørskov, Modeling the electrochemical hydrogen oxidation and evolution reactions on the basis of density functional theory calculations, The Journal of Physical Chemistry C 114(42) (2010) 18182-18197.

[34] J.H. Montoya, C. Tsai, A. Vojvodic, J.K. Nørskov, The Challenge of Electrochemical Ammonia Synthesis: A New Perspective on the Role of Nitrogen Scaling Relations, Chemsuschem 8(13) (2015) 2180-2186.

[35] D. Yang, T. Chen, Z. Wang, Electrochemical reduction of aqueous nitrogen ( $\mathrm{N} 2$ ) at a low overpotential on (110)-oriented Mo nanofilm, Journal of Materials Chemistry A 5(36) (2017) 18967-18971.

[36] M. Nazemi, S.R. Panikkanvalappil, M.A. El-Sayed, Enhancing the rate of electrochemical nitrogen reduction reaction for ammonia synthesis under 
ambient conditions using hollow gold nanocages, Nano Energy 49 (2018) 316-323.

[37] H. Huang, L. Xia, X. Shi, A.M. Asiri, X. Sun, Ag nanosheets for efficient electrocatalytic $\mathrm{N} 2$ fixation to $\mathrm{NH} 3$ under ambient conditions, Chem. Commun. 54(81) (2018) 11427-11430.

[38] M.-A. Légaré, G. Bélanger-Chabot, R.D. Dewhurst, E. Welz, I. Krummenacher, B. Engels, H. Braunschweig, Nitrogen fixation and reduction at boron, Science 359(6378) (2018) 896-900.

[39] C. Liu, Q. Li, J. Zhang, Y. Jin, D.R. MacFarlane, C. Sun, Theoretical evaluation of possible 2D boron monolayer in $\mathrm{N}_{2}$ electrochemical conversion into ammonia, The Journal of Physical Chemistry C 122(44) (2018) 2526825273.

[40] X. Zhang, T. Wu, H. Wang, R. Zhao, H. Chen, T. Wang, P. Wei, Y. Luo, Y. Zhang, X. Sun, Boron Nanosheet: An Elemental Two-Dimensional (2D) Material for Ambient Electrocatalytic $\mathrm{N}_{2}$-to- $\mathrm{NH}_{3}$ Fixation in Neutral Media, ACS Catalysis 9 (2019) 4609-4615.

[41] L. Zhang, L.X. Ding, G.F. Chen, X. Yang, H. Wang, Ammonia Synthesis Under Ambient Conditions: Selective Electroreduction of Dinitrogen to Ammonia on Black Phosphorus Nanosheets, Angew. Chem. 131(9) (2019) 2638-2642.

[42] B. Qiao, A. Wang, X. Yang, L.F. Allard, Z. Jiang, Y. Cui, J. Liu, J. Li, T. Zhang, Single-atom catalysis of CO oxidation using Pt 1/FeO x, Nature chemistry 3(8) (2011) 634.

[43] Z.W. Chen, L.X. Chen, C. Yang, Q. Jiang, Atomic (Single, Double, and Triple Atoms) Catalysis: Frontiers, Opportunities, and Challenges, Journal of Materials Chemistry A 7(8) (2019).

[44] Y. Wang, J. Mao, X. Meng, L. Yu, D. Deng, X. Bao, Catalysis with two-dimensional materials confining single atoms: concept, design, and applications, Chem. Rev. 119(3) (2018) 1806-1854.

[45] A. Wang, J. Li, T. Zhang, Heterogeneous single-atom catalysis, Nature Reviews Chemistry 2(6) (2018) 65.

[46] N. Xuan, J. Chen, J. Shi, Y. Yue, P. Zhuang, K. Ba, Y. Sun, J. Shen, Y. Liu, B. Ge, Single-Atom Electroplating on Two Dimensional Materials, Chem. Mater. 31(2) (2018) 429435.

[47] B.M. Hoffman, D.R. Dean, L.C. Seefeldt, Climbing nitrogenase: toward a mechanism of enzymatic nitrogen fixation, Acc. Chem. Res. 42(5) (2009) 609-619.

[48] X.F. Li, Q.K. Li, J. Cheng, L. Liu, Q. Yan, Y. Wu, X.H. Zhang, Z.Y. Wang, Q. Qiu, Y. Luo, Conversion of Dinitrogen to Ammonia by FeN3-Embedded Graphene, J. Am. Chem. Soc. 138(28) (2016) 8706.

[49] Z. Wei, Y. Zhang, S. Wang, C. Wang, J. Ma, Fe-doped phosphorene for the nitrogen reduction reaction, Journal of Materials Chemistry A 6(28) (2018) 1379013796.
[50] C. Choi, S. Back, N.-Y. Kim, J. Lim, Y.-H. Kim, Y. Jung, Suppression of hydrogen evolution reaction in electrochemical $\mathrm{N}_{2}$ reduction using single-atom catalysts: A computational guideline, ACS Catalysis 8(8) (2018) 7517-7525.

[51] Y. Nishibayashi, Recent progress in transition-metalcatalyzed reduction of molecular dinitrogen under ambient reaction conditions, Inorg. Chem. 54(19) (2015) 9234-9247.

[52] H. Tanaka, Y. Nishibayashi, K. Yoshizawa, Interplay between theory and experiment for ammonia synthesis catalyzed by transition metal complexes, Acc. Chem. Res. 49(5) (2016) 987-995.

[53] J. Zhao, Z. Chen, Single Mo atom supported on defective boron nitride monolayer as an efficient electrocatalyst for nitrogen fixation: a computational study, J. Am. Chem. Soc. 139(36) (2017) 12480-12487.

[54] C. Ling, X. Bai, Y. Ouyang, A. Du, J. Wang, Single molybdenum atom anchored on $\mathrm{N}$-doped carbon as a promising electrocatalyst for nitrogen reduction into ammonia at ambient conditions, The Journal of Physical Chemistry C 122(29) (2018) 16842-16847.

[55] P. Ou, X. Zhou, F. Meng, C. Chen, Y. Chen, J. Song, Single Molybdenum Center Supported on N-Doped Black Phosphorus as an Efficient Electrocatalyst for Nitrogen Fixation, Nanoscale (2019).

[56] H. Yin, S.-L. Li, L.-Y. Gan, P. Wang, Pt-embedded in monolayer $\mathrm{gC} 3 \mathrm{~N} 4$ as a promising single-atom electrocatalyst for ammonia synthesis, Journal of Materials Chemistry A 7(19) (2019) 11908-11914.

[57] Z. Chen, X. Lang, Q. Jiang, Discovery of cobweb-like MoC 6 and its application for nitrogen fixation, Journal of Materials Chemistry A 6(20) (2018) 9623-9628.

[58] X. Yu, P. Han, Z. Wei, L. Huang, Z. Gu, S. Peng, J. Ma, G. Zheng, Boron-doped graphene for electrocatalytic $\mathrm{N}_{2}$ reduction, Joule 2(8) (2018) 1610-1622.

[59] C. Ling, X. Niu, Q. Li, A. Du, J. Wang, Metal-free single atom catalyst for $\mathrm{N}_{2}$ fixation driven by visible light, J. Am. Chem. Soc. 140(43) (2018) 14161-14168.

[60] S. Ji, Z. Wang, J. Zhao, A boron-interstitial doped C 2 N layer as a metal-free electrocatalyst for $\mathrm{N} 2$ fixation: a computational study, Journal of Materials Chemistry A 7(5) (2019) 2392-2399.

[61] X. Lv, W. Wei, F. Li, B. Huang, Y. Dai, Metal-Free B@ g-CN Visible/Infrared Light-Driven Single Atom Photocatalyst Enables Spontaneous Dinitrogen Reduction to Ammonia, Nano Lett. (2019).

[62] C. Liu, Q. Li, C. Wu, J. Zhang, Y. Jin, D.R. MacFarlane, C. Sun, Single-boron catalysts for nitrogen reduction reaction, J. Am. Chem. Soc. (2019).

[63] Y. Abghoui, A.L. Garden, J.G. Howalt, T. Vegge, E. Skúlason, Electroreduction of $\mathrm{N}_{2}$ to ammonia at ambient conditions on mononitrides of $\mathrm{Zr}, \mathrm{Nb}, \mathrm{Cr}$, and V: A DFT 
guide for experiments, Acs Catalysis 6(2) (2015) 635646.

[64] Q. Li, L. He, C. Sun, X. Zhang, Computational study of $\mathrm{MoN}_{2}$ monolayer as electrochemical catalysts for nitrogen reduction, The Journal of Physical Chemistry $\mathrm{C}$ 121(49) (2017) 27563-27568.

[65] L. Zhang, X. Ji, X. Ren, Y. Luo, X. Shi, A.M. Asiri, B. Zheng, $X$. Sun, Efficient electrochemical $\mathrm{N}_{2}$ reduction to $\mathrm{NH} 3$ on MoN nanosheets array under ambient conditions, ACS Sustainable Chemistry \& Engineering 6(8) (2018) 95509554.

[66] L. Zhang, X. Ji, X. Ren, Y. Ma, X. Shi, Z. Tian, A.M. Asiri, L. Chen, B. Tang, X. Sun, Electrochemical ammonia synthesis via nitrogen reduction reaction on a MoS2 catalyst: theoretical and experimental studies, Adv. Mater. 30(28) (2018) 1800191.

[67] X. Li, T. Li, Y. Ma, Q. Wei, W. Qiu, H. Guo, X. Shi, P. Zhang, A.M. Asiri, L. Chen, Boosted Electrocatalytic $\mathrm{N}_{2}$ Reduction to NH3 by Defect-Rich MoS2 Nanoflower, Advanced Energy Materials 8(30) (2018) 1801357.

[68] B.H. Suryanto, D. Wang, L.M. Azofra, M. Harb, L. Cavallo, R. Jalili, D.R. Mitchell, M. Chatti, D.R. MacFarlane, MoS2 polymorphic engineering enhances selectivity in the electrochemical reduction of nitrogen to ammonia, ACS Energy Letters 4(2) (2018) 430-435.

[69] A.-Y. Lu, H. Zhu, J. Xiao, C.-P. Chuu, Y. Han, M.-H. Chiu, C.-C. Cheng, C.-W. Yang, K.-H. Wei, Y. Yang, Janus monolayers of transition metal dichalcogenides, Nature nanotechnology 12(8) (2017) 744.

[70] J. Zhang, S. Jia, I. Kholmanov, L. Dong, D. Er, W. Chen, H. Guo, Z. Jin, V.B. Shenoy, L. Shi, Janus monolayer transition-metal dichalcogenides, ACS nano 11(8) (2017) 8192-8198.

[71] C. Xia, W. Xiong, J. Du, T. Wang, Y. Peng, J. Li, Universality of electronic characteristics and photocatalyst applications in the two-dimensional Janus transition metal dichalcogenides, Physical Review B 98(16) (2018) 165424.

[72] D. Er, H. Ye, N.C. Frey, H. Kumar, J. Lou, V.B. Shenoy, Prediction of enhanced catalytic activity for hydrogen evolution reaction in Janus transition metal dichalcogenides, Nano Lett. 18(6) (2018) 3943-3949.

[73] L. Li, B. Li, Q. Guo, B. Li, Theoretical Screening of SingleAtom Anchored MoSSe Nanosheets for Electrocatalytic $\mathrm{N}_{2}$ Fixation, The Journal of Physical Chemistry C (2019).

[74] R. Michalsky, Y.-J. Zhang, A.J. Medford, A.A. Peterson, Departures from the adsorption energy scaling relations for metal carbide catalysts, The Journal of Physical Chemistry C 118(24) (2014) 13026-13034.

[75] Y. Shi, Y. Yang, Y.-W. Li, H. Jiao, Mechanisms of $\mathrm{Mo}_{2} \mathrm{C}$ (101)-catalyzed furfural selective hydrodeoxygenation to 2-methylfuran from computation, ACS Catalysis 6(10) (2016) 6790-6803.

[76] W. Liu, B. Chen, X. Duan, K.-H. Wu, W. Qi, X. Guo, B. Zhang, D. Su, Molybdenum carbide modified nanocarbon catalysts for alkane dehydrogenation reactions, ACS Catalysis 7(9) (2017) 5820-5827.

[77] H. Cheng, L.X. Ding, G.F. Chen, L. Zhang, J. Xue, H. Wang, Molybdenum carbide nanodots enable efficient electrocatalytic nitrogen fixation under ambient conditions, Adv. Mater. 30(46) (2018) 1803694. 